\title{
Article
}

\section{To align or not to align? Research methods and its relationship with dissertation marks across sport undergraduate degree programmes within a UK-based HE institution}

Houghton, Laura J, Williams, Emily L, Massey, Hollie, Page, Richard $M$ and Bostock, John

Available at http://clok.uclan.ac.uk/17632/

Houghton, Laura J, Williams, Emily L, Massey, Hollie ORCID: 0000-0002-97938702, Page, Richard M and Bostock, John (2017) To align or not to align? Research methods and its relationship with dissertation marks across sport undergraduate degree programmes within a UK-based HE institution. Journal of Hospitality, Leisure, Sport and Tourism Education, 20 . pp. 101-109. ISSN $1473-8376$

It is advisable to refer to the publisher's version if you intend to cite from the work. http://dx.doi.org/10.1016/j.jhlste.2017.04.005

For more information about UCLan's research in this area go to http://www.uclan.ac.uk/researchgroups/ and search for <name of research Group>.

For information about Research generally at UCLan please go to http://www.uclan.ac.uk/research/

All outputs in CLoK are protected by Intellectual Property Rights law, including Copyright law. Copyright, IPR and Moral Rights for the works on this site are retained by the individual authors and/or other copyright owners. Terms and conditions for use of this material are defined in the policies page. 


\title{
To align or not to align? Research methods and its relationship with dissertation marks across Sport undergraduate degree programmes within a UK-based HE institution
}

\begin{abstract}
Much research has referred to the complexity of research methods modules within undergraduate degree programmes. Less attention has been paid to the objective understanding of alignment between research methods and final year dissertations. This study explored relationships across Sport and Exercise Science (SES) and Sports Therapy (ST) programmes within a UK-based Higher Education institution. Analysis revealed females $(\mathrm{N}=73)$ outperformed males ( $\mathrm{N}=117)$ at Levels $4 / 5$, and SES students outperformed ST at Level 6. The Level 5 statistics assessment explained the lowest variance in the dissertation, suggesting poor alignment in curriculum design. Future research should consider the efficacy of statistics-based modules.
\end{abstract}

Keywords: constructive alignment, statistics, gender, assessment, research methods 


\section{Introduction}

Over the past decade, Higher Education (HE) in the United Kingdom has undergone significant change. More young people than ever are opting to enter $\mathrm{HE}$, with an increase of 22,000 university places being accepted between the 2013 and 2014 cycles (UCAS, 2013), despite the increase in tuition fees. It is universally recognised that $\mathrm{HE}$ aims to advance and disseminate knowledge through a culmination of teaching and learning (Brennan, Durazzi \& Sene, 2013). In more recent years, however, it has also become an expectation that universities provide access to advanced vocational skills and professional training in order to fully prepare students for employment (Haigh \& Clifford, 2011). It can be argued that this places increased pressure on $\mathrm{HE}$ institutions to ensure that all students receive a high quality university experience, regardless of their socio-economic background (Leathwood \& O' Connell, 2003; Marginson, 2016). Additionally, differences in both academic and socio-economic background may lead to students entering HE with varying levels of expertise related to academic writing and critical analysis skills which may also pose a significant challenge for universities and academic staff (Bostock \& Wood, 2012).

Within science undergraduate degree programmes, there is evidence of a 1.5:1 male to female ratio, with this increasing seven-fold in respect to science teaching staff (Webb, Lubinski \& Persson Benbow, 2002). Additionally, it has been suggested that academic performance is also influenced by gender, with $50 \%$ more male students achieving first class degrees than their female counterparts (McNabb, Pal \& Loanes, 2002). However, at the opposite end of the spectrum, males are also more likely to achieve third class degrees or fails than females. Sander and Sanders (2007) suggest that at the University of Wales, male undergraduates receive a final degree mark that is $2 \%$ lower than females, although this does vary across degree programme. Attempts have been made to explain these gender differences, with researchers noting that they may occur as a result of a multitude of factors. These include the quality of the institution for which gender types are predisposed to attend, biological factors/ability, gender stereotyping relating to assessment and type of programme studied (McNabb et al., 2002). Recent research in the field of education has also noted the potentially negative impact a male environment may have on student (particularly female student) learning and overall experiences, labelling this phenomenon 'lad culture' (Phillips \& Young 2011). It is arguably then essential that Level 4 modules provide all students with the 
necessary core skills to succeed throughout their university study, regardless of student education, gender or background.

Much research has also referred to the complex nature of research methods modules within undergraduate degree programmes (Ball \& Pelco, 2006; Lehti \& Lehtinen, 2005; Braguglia \& Jackson, 2012). These types of modules have been widely criticised by both staff and students within HE for being 'uninteresting' and 'dry' (Schutt, Blalock \& Wagenaar 1984), with students feeling nervous and often anxious about the topic and subsequently displaying a 'scrape by with just a pass' attitude, particularly for more applied programmes (Campisi \& Finn, 2011). This in turn may lead to difficulties with students progressing through levels of study and/or degree completion. This type of module could also be seen as particularly problematic and/or off-putting for female students who often perform worse than their male counterparts in maths-science subjects. (McNabb et al., 2002).

As noted by Gladys, Nicholas and Crispen (2012), difficulties experienced within research methods modules may negatively impact on the student's dissertation project, where the concepts acquired, particularly statistical techniques, need to be applied. Interestingly, while students in the main held positive views of the relevance of a research methods module within a teacher education course, around $80 \%$ of all students viewed the module as both stressful and difficult (Gladys et al., 2012). This leads to considerable pressure being placed on lecturers, who are faced with the challenge of making research methods modules interesting to students whilst ensuring they gain the necessary knowledge of the complexities of research and also have the means to apply that knowledge when conducting their own research project (Edwards \& Thatcher, 2004).

Whilst a number of studies have focused on the views of staff and students relating to problems with research methods modules, particularly those involving quantitative approaches, less attention has been given to the objective understanding of the alignment between research methods modules at Level 4 and 5, and final year dissertation modules. For example, Gladys et al., (2012) focused on the views of students undertaking research methods modules, yet failed to thoroughly investigate the precise link between performance within research methods and final year projects. Similarly, Benson and Blackman (2003) used an activity-based approach to restructure the design of a research methods module. They 
concluded that students struggled to make the perceptual link between the learning outcomes of the module and the application of this knowledge within their own final year dissertation research project.

Despite these clearly formulated issues within $\mathrm{HE}$, there is a paucity of research which investigates the teaching of research methods and what students actually learn within these modules (Wagner, Garner \& Kawaulich, 2011). Furthermore, it has yet to be implicitly investigated if research methods modules are adequately preparing students for carrying out their own research projects at Level 6, i.e. if there is a relationship between performance in research methods and dissertation modules. The aim of this study was to explore the relationships between research methods assessments and modules across Levels 4-6 of Sport and Exercise Science (SES) and Sports Therapy (ST) undergraduate programmes at a UK-based university.

\section{Method}

\section{Participants}

Following the attainment of ethical approval from the University Research Ethics Committee, student marks for research methods modules, and individual assessments, were retrieved from departmental archives. To ensure anonymity, all student data was prescribed a unique ID and information related to any demographic factors such as home postcode were removed and not analysed as part of the current study. The research team adhered to the principles outlined within the University's Research Ethics Framework (2014) alongside the British Educational Research Association guidelines and ethical framework, throughout the study. The sample comprised 190 students (males $=117$, females $=73$ ) who studied on Sport and Exercise Science (SES: Total $=93$; Males $=69 ;$ Females $=24)$ and Sports Therapy $($ ST: Total $=$ 97; Males $=48$; Females $=49$ ) undergraduate degree programmes in 2009-2012 and 20102013. Inclusion criteria required that students completed all elements of their respective programme, with none submissions excluded from the analysis.

\section{Data}

The SES and ST students both completed the same research method modules at Levels 4 and 5 , and the same dissertation module at Level 6 . The aforementioned modules were delivered 
by the same members of staff and did not undergo any minor modifications between 2009 and 2013. With the exception of the research methods and dissertation modules, no other modules were shared between the two programmes. Student marks were collated for individual assignments within the research methods and dissertation modules, as well as the overall mark for each module. The Level 4 research methods module $(L 4(T))$ comprised the completion of a single written examination. The Level 5 research methods module $(\mathrm{L} 5(\mathrm{~T}))$ consisted of two methods of summative assessment: a statistics workbook (L5(STATS)) with a $40 \%$ weighting, and a written dissertation proposal (L5(PROP)) worth $60 \%$. The dissertation module $(\mathrm{L} 6(\mathrm{~T}))$ contained two methods of summative assessment: an $80 \%$ weighted dissertation research project (L6(DISS)), and a 20\% weighted oral presentation (L6(PRES)).

\section{Statistical Analyses}

Assessment marks were inputted into Microsoft Excel as a percentage of a 100-point scale. All analyses were completed using PASW Statistics Editor 21.0 for Windows (SPSS Inc, Chicago, USA) with a significance level set at $p<0.05$. Student T-tests were conducted to compare group means for gender and programme as well as for subgroups: male SES, female SES, male ST and female ST. Correlation coefficients (Pearson's $r$ ) were calculated for comparisons of $L 4(T)$ to $L 5(T), L 4(T)$ to $L 6(T), L 5(T)$ to $L 6(T), L 4(T)$ to L6(DISS), L5(STATS) to L6(DISS), and L5(PROP) to L6(DISS). The Pearson's $r$ values were used to calculate $r^{2}$ values to explain the variance in the predictor variables. All data is reported as mean \pm (standard deviation; SD) unless otherwise stated.

\section{Results}

\section{Descriptive Analysis}

Mean (SD) percentage marks for each individual assessment and overall module marks for Levels 4-6 are presented in Table 1. Females typically performed better than their male counterparts, with an average mark of 56.6 versus $55 \%$. The range of marks fell between $33.7-$ $83 \%$ (Interquartile Range; IQR $=46.7$ ) for females and $29.7-82 \%(I Q R=52.3)$ for males. Between-gender T-tests identified that females performed significantly better on L5(STATS) (Mean Difference; $M D=6.7 \% ; p=0.004)$ and $L 5(T)(M D=3.8 \% ; p=0.036)$. The comparison between male and female SES students identified that females achieved higher marks than males for $L 4(T)(M D=9.3 \% ; p=0.005)$ and $L 5(S T A T S)(M D=8.7 \% ; p=0.033)$. 
Table 1. Mean (SD) percentage marks achieved for assessments and modules across Levels 4-6 in undergraduate Sport and Exercise Science (SES) and Sports Therapy (ST) degrees

\begin{tabular}{r|cccccccc} 
& Overall Average & L4(T) & L5(STATS) & L5(PROP) & L5(T) & L6(PRES) & L6(DISS) \\
\hline Total cohort & $55.7(10.3)$ & $55.1(14.0)$ & $53.7(15.8)$ & $55.0(13.1)$ & $54.5(12.3)$ & $57.4(11.8)$ & $57.2(12.3)$ & $57.3(12.2)$ \\
Males & $55.0(10.4)$ & $54.0(14.0)$ & $51.1(16.3)$ & $54.2(13.7)$ & $53.1(12.6)$ & $58.2(10.5)$ & $57.8(12.9)$ & $58.0(11.9)$ \\
Females & $56.6(10.3)$ & $56.9(13.8)$ & $57.8(14.1)^{*}$ & $56.2(12.0)$ & $56.9(11.3)^{*}$ & $56.0(13.5)$ & $56.3(11.3)$ & $56.2(12.7)$ \\
SES & $56.4(10.8)$ & $55.1(14.2)$ & $51.9(17.3)$ & $56.1(13.6)$ & $54.5(13.3)$ & $60.2(10.5)^{\#}$ & $59.7(13.6)^{\#}$ & $60.0(12.7)^{\#}$ \\
ST & $54.9(9.8)$ & $55.2(13.9)$ & $55.3(14.1)$ & $53.9(12.6)$ & $54.6(11.2)$ & $54.6(12.3)$ & $54.8(10.4)$ & $55.0(11.4)$ \\
Male SES & $54.9(10.7)$ & $52.7(14.9)$ & $49.7(16.9)$ & $55.1(13.8)$ & $53.0(13.1)$ & $59.7(10.1)$ & $59.3(14.4)$ & $59.1(13.2)$ \\
Female SES & $60.7(10.0)$ & $62.0(9.2)^{\ddagger}$ & $58.4(17.1)^{\ddagger}$ & $59.0(12.7)$ & $58.8(13.4)$ & $61.6(11.6)$ & $61.0(11.2)$ & $61.3(11.3)$ \\
Male ST & $55.2(9.9)$ & $56.0(12.7)$ & $55.1(15.3)$ & $52.9(13.7)$ & $53.2(12.1)$ & $56.0(10.8)$ & $55.7(10.1)$ & $56.4(9.8)$ \\
Female ST & $54.7(9.9)$ & $54.4(15.1)$ & $57.5(12.5)$ & $54.8(11.5)$ & $56.0(10.2)$ & $53.2(13.6)$ & $54.0(10.7)$ & $53.7(12.7)$
\end{tabular}

* denotes a significantly higher mark than males $(\mathrm{p}<0.05)$

\# denotes a significantly higher mark than Sports Therapy students $(p<0.05)$

$\ddagger$ denotes a significantly higher make than male Sport and Exercise Science students $(p<0.005)$ 
Overall, SES students performed better than ST students across the modules, with an average mark of 56.4 compared to $54.9 \%$. Significant differences between the SES and ST programmes were identified across Level 6, with SES achieving higher scores than ST in both the L6(PRES) $(M D=5.6 \% ; p=0.001)$ and the L6(DISS) assessments (MD $=4.9 \% ; p=0.006)$. This expectedly produced a significantly higher percentage for SES in the L6(T) mark than ST (MD = 4.7\%; $p=$ 0.008).

Of the four subgroups, female SES students consistently achieved the highest marks for each Level 4-6 module, with a mean of $60.7 \%$. The largest discrepancy between marks occurred at Level 4 between the male and female SES students with a difference of 9.3\%. Both female SES students and male ST students performed worse at Level 5 than Level 4, whereas male SES and female ST improved their marks. Female ST students were the only subgroup not to improve performance from Level 5-6, instead demonstrating a $2.3 \%$ attenuation. Male SES students showed the largest overall improvement across their degree programme, improving by $6.4 \%$ from Level 4-6, with the largest between-Level increase of $6.1 \%$ from Level 5 to 6 .

\section{Correlations}

Relationships between module marks across Levels 4-6, as well as the relationships between L4(T), L5(STATS) and L5(PROP) with L6(DISS), were all positively correlated. As an overall cohort, as well as for individual male, female, SES and ST groups, all relationships were significantly correlated $(p<0.05)$, but correlation coefficients $\left(r^{2}\right)$ ranged from 0.06 to 0.32 (Table 2.1-2.5). Stronger coefficients were found in the subgroups; up to a coefficient of 0.53 (Tables 2.6-2.9). Of the non-significant relationships identified in the sub groups of male SES, females SES, male ST and female ST, coefficients ranged from 0.05 to 0.08 . 
Table 2.1 Correlation coefficients $\left(r^{2}\right)$ and significance values for the relationships between assessments and modules across Levels 4-6 for a whole cohort of SES and ST undergraduate students

\begin{tabular}{|c|c|c|c|c|c|c|}
\hline & $\mathrm{L} 4(\mathrm{~T})$ & L5(STATS) & L5(PROP) & $\mathrm{L} 5(\mathrm{~T})$ & L6(DISS) & $\mathrm{L6}(\mathrm{T})$ \\
\hline$L 4(T)$ & & & & $r^{2}=0.17 ; p<0.001$ & $r^{2}=0.20 ; p<0.001$ & $r^{2}=0.25 ; p<0.001$ \\
\hline L5(STATS) & & & & & $r^{2}=0.07 ; p<0.001$ & \\
\hline L5(PROP) & & & & & $r^{2}=0.23 ; p<0.001$ & \\
\hline $\mathrm{L} 5(\mathrm{~T})$ & $r^{2}=0.17 ; p<0.001$ & & & & & $r^{2}=0.25 ; p<0.001$ \\
\hline L6(DISS) & $r^{2}=0.20 ; p<0.001$ & $r^{2}=0.07 ; p<0.001$ & $r^{2}=0.23 ; p<0.001$ & & & \\
\hline$L 6(T)$ & $r^{2}=0.25 ; p<0.001$ & & & $r^{2}=0.25 ; p<0.001$ & & \\
\hline
\end{tabular}

Table 2.2 Correlation coefficients $\left(r^{2}\right)$ and significance values for the relationships between assessments and modules across Levels 4-6 for male SES and ST undergraduate students

\begin{tabular}{|c|c|c|c|c|c|c|}
\hline & $\mathrm{L} 4(\mathrm{~T})$ & L5(STATS) & L5(PROP) & $\mathrm{L} 5(\mathrm{~T})$ & L6(DISS) & L6(T) \\
\hline $\mathrm{L} 4(\mathrm{~T})$ & & & & $r^{2}=0.16 ; p<0.001$ & $r^{2}=0.22 ; p<0.001$ & $r^{2}=0.26 ; p<0.001$ \\
\hline L5(STATS) & & & & & $r^{2}=0.06 ; p=0.011$ & \\
\hline L5(PROP) & & & & & $r^{2}=0.21 ; p<0.001$ & \\
\hline $\mathrm{L} 5(\mathrm{~T})$ & $r^{2}=0.16 ; p<0.001$ & & & & & $r^{2}=0.25 ; p<0.001$ \\
\hline L6(DISS) & $r^{2}=0.22 ; p<0.001$ & $r^{2}=0.06 ; p=0.011$ & $r^{2}=0.21 ; p<0.001$ & & & \\
\hline $\mathrm{L6}(\mathrm{T})$ & $r^{2}=0.26 ; p<0.001$ & & & $r^{2}=0.25 ; p<0.001$ & & \\
\hline
\end{tabular}

Table 2.3 Correlation coefficients $\left(r^{2}\right)$ and significance values for the relationships between assessments and modules across Levels 4-6 for female SES and ST undergraduate students

\begin{tabular}{|c|c|c|c|c|c|c|}
\hline & $\mathrm{L} 4(\mathrm{~T})$ & L5(STATS) & L5(PROP) & $\mathrm{L} 5(\mathrm{~T})$ & L6(DISS) & $\mathrm{L} 6(\mathrm{~T})$ \\
\hline L4(T) & & & & $r^{2}=0.15 ; p=0.001$ & $r^{2}=0.20 ; p<0.001$ & $r^{2}=0.22 ; p<0.001$ \\
\hline L5(STATS) & & & & & $r^{2}=0.15 ; p=0.001$ & \\
\hline L5(PROP) & & & & & $r^{2}=0.28 ; p<0.001$ & \\
\hline $\mathrm{L} 5(\mathrm{~T})$ & $r^{2}=0.15 ; p=0.001$ & & & & & $r^{2}=0.32 ; p<0.001$ \\
\hline L6(DISS) & $r^{2}=0.20 ; p<0.001$ & $r^{2}=0.15 ; p=0.001$ & $r^{2}=0.28 ; p<0.001$ & & & \\
\hline L6(T) & $r^{2}=0.22 ; p<0.001$ & & & $r^{2}=0.32 ; p<0.001$ & & \\
\hline
\end{tabular}


Table 2.4 Correlation coefficients $\left(r^{2}\right)$ and significance values for the relationships between assessments and modules across Levels 4-6 for male and female SES undergraduate students

\begin{tabular}{llllll}
\hline & L4(T) & L5(STATS) & L5(PROP) & L5(T) & L6(DISS) \\
\hline $\begin{array}{l}\text { L4(T) } \\
\text { L5(STATS) }\end{array}$ & & & $r^{2}=0.18 ;<0.001$ & $r^{2}=0.19 ; p<0.001$ & $r^{2}=0.23 ; p<0.001$ \\
L5(PROP) & & & & $r^{2}=0.10 ; p=0.003$ \\
L5(T) & $r^{2}=0.18 ; p<0.001$ & & & $r^{2}=0.19 ; p<0.001$ \\
L6(DISS) & $r^{2}=0.19 ; p<0.001$ & $r^{2}=0.10 ; p=0.003$ & $r^{2}=0.19 ; p<0.001$ & \\
L6(T) & $r^{2}=0.23 ; p<0.001$ & & & $r^{2}=0.27 ; p<0.001$ &
\end{tabular}

Table 2.5 Correlation coefficients $\left(r^{2}\right)$ and significance values for the relationships between assessments and modules across Levels 4-6 for male and female ST undergraduate students

\begin{tabular}{l|llllll}
\hline & L4(T) & L5(STATS) & L5(PROP) & L5(T) & L6(DISS) & L6(T) \\
\hline L4(T) & & & $r^{2}=0.15 ; p<0.001$ & $r^{2}=0.25 ; p<0.001$ & $r^{2}=0.30 ; p<0.001$ \\
L5(STATS) & & & & $r^{2}=0.07 ; p=0.007$ & \\
L5(PROP) & & & & $r^{2}=0.28 ; p<0.001$ & \\
L5(T) & $r^{2}=0.15 ; p<0.001$ & & & & $r^{2}=0.26 ; p<0.001$ \\
L6(DISS) & $r^{2}=0.25 ; p<0.001$ & $r^{2}=0.07 ; p=0.007$ & $r^{2}=0.28 ; p<0.001$ & & \\
L6(T) & $r^{2}=0.30 ; p<0.001$ & & & $r^{2}=0.26 ; p<0.001$ & &
\end{tabular}

Table 2.6 Correlation coefficients $\left(r^{2}\right)$ and significance values for the relationships between assessments and modules across Levels 4-6 for male SES undergraduate students

\begin{tabular}{l|llllll}
\hline & L4(T) & L5(STATS) & L5(PROP) & L5(T) & L6(DISS) & L6(T) \\
\hline L4(T) & & & $r^{2}=0.12 ; p=0.005$ & $r^{2}=0.18 ; p<0.001$ & $r^{2}=0.21 ; p<0.001$ \\
L5(STATS) & & & & $r^{2}=0.05 ; p=0.054$ & \\
L5(PROP) & & & & $r^{2}=0.16 ; p=0.001$ & \\
\hline L5(T) & $r^{2}=0.12 ; p=0.005$ & & & & $r^{2}=0.21 ; p<0.001$ \\
L6(DISS) & $r^{2}=0.18 ; p<0.001$ & $r^{2}=0.05 ; p=0.054$ & $r^{2}=0.16 ; p=0.001$ & & & \\
L6(T) & $r^{2}=0.21 ; p<0.001$ & & & $r^{2}=0.21 ; p<0.001$ & &
\end{tabular}

Table 2.7 Correlation coefficients $\left(r^{2}\right)$ and significance values for the relationships between assessments and modules across Levels 4-6 for female SES undergraduate students

\begin{tabular}{lllllll}
\hline & L4(T) & L5(STATS) & L5(PROP) & L5(T) & L6(DISS) \\
\hline $\begin{array}{l}\text { L4(T) } \\
\text { L5(STATS) }\end{array}$ & & & $r^{2}=0.53 ; p<0.001$ & $r^{2}=0.17 ; p=0.006$ & $r^{2}=0.34 ; p=0.003$ \\
$\begin{array}{l}\text { L5(PROP) } \\
\text { L5(T) }\end{array}$ & & & & $r^{2}=0.34 ; p=0.003$ \\
L6(STATS) & $r^{2}=0.53 ; p<0.001$ & & & $r^{2}=0.34 ; p=0.003$ \\
L6(T) & $r^{2}=0.17 ; p=0.006$ & $r^{2}=0.34 ; p=0.003$ & $r^{2}=0.34 ; p=0.003$ & & $r^{2}=0.52 ; p<0.001$ \\
\hline
\end{tabular}


Table 2.8 Correlation coefficients $\left(r^{2}\right)$ and significance values for the relationships between assessments and modules across Levels 4-6 for male ST undergraduate students

\begin{tabular}{l|lll|l|l} 
& L4(T) & L5(STATS) & L5(PROP) & L5(T) & L6(DISS) \\
\hline $\begin{array}{l}\text { L4(T) } \\
\text { L5(STATS) }\end{array}$ & & & $r^{2}=0.29 ; p<0.001$ & $r^{2}=0.42 ; p<0.001$ & $r^{2}=0.46 ; p<0.001$ \\
$\begin{array}{l}\text { L5(PROP) } \\
\text { L5(T) }\end{array}$ & & & & $r^{2}=0.09 ; p=0.036$ \\
L6(DISS) & $r^{2}=0.29 ; p<0.001$ & & & $r^{2}=0.37 ; p<0.001$ \\
L6(T) & $r^{2}=0.42 ; p<0.001$ & $r^{2}=0.09 ; p=0.036$ & $r^{2}=0.37 ; p<0.001$ & & $r^{2}=0.36 ; p<0.001$ \\
\hline
\end{tabular}

Table 2.9 Correlation coefficients $\left(r^{2}\right)$ and significance values for the relationships between assessments and modules across Levels 4-6 for female ST undergraduate students

\begin{tabular}{llllll}
\hline & L4(T) & L5(STATS) & L5(PROP) & L5(T) & L6(DISS) \\
\hline $\begin{array}{l}\text { L4(T) } \\
\text { L5(STATS) }\end{array}$ & & & $r^{2}=0.07 ; p=0.57$ & $r^{2}=0.14 ; p=0.007$ & $r^{2}=0.22 ; p=0.001$ \\
L5(PROP) & & & & $r^{2}=0.08 ; p=0.056$ \\
L5(T) & $r^{2}=0.07 ; p=0.57$ & & & \\
L6(DISS) & $r^{2}=0.14 ; p=0.007$ & $r^{2}=0.08 ; p=0.056$ & $r^{2}=0.22 ; p=0.001$ & & $r^{2}=0.24 ; p<0.001$ \\
L6(T) & $r^{2}=0.22 ; p=0.001$ & & & $r^{2}=0.24 ; p<0.001$ &
\end{tabular}


$L 4(T)$ and L6(DISS)

Overall, a relationship of $r^{2}=0.20$ was found for $L 4(T)$ to $L 6$ (DISS) for the whole cohort and a range of $r^{2}=0.19-0.22$ for each gender and programme group. A stronger relationship was found for male ST students $\left(r^{2}=0.42\right)$ than all other subgroups $\left(r^{2}=0.14-18\right)$.

\section{L5(STATS) and L6(DISS)}

The lowest overall cohort relationship was found between L5(STATS) and L6(DISS) $\left(r^{2}=0.17\right)$, with consistently weak relationships across genders and programmes $\left(r^{2}=0.15-0.18\right)$. Furthermore, non-significant relationships were identified for male SES $\left(r^{2}=0.05 ; p=0.054\right)$ and female ST students $\left(r^{2}=0.08 ; p=0.056\right)$.

\section{L5(PROP) and L6(DISS)}

Overall, the relationship between L5(PROP) and L6(DISS) was $r^{2}=0.23$, with females and ST students demonstrating stronger relationships $\left(r^{2}=0.28\right)$ than males $\left(r^{2}=0.21\right)$ and SES students $\left(r^{2}=0.19\right)$. Analysis of the subgroups identified that these differences stem from stronger relationships for female SES $\left(r^{2}=0.32\right)$ and male ST students $\left(r^{2}=0.37\right)$.

$$
L 4(T)-L 6(T)
$$

The average relationship between $L 4(T)$ and $L 5(T)$ for the whole cohort was $r^{2}=0.17$, which was similar to each of the gender and programme groups $\left(r^{2}=0.15-0.18\right)$. When analysed by subgroup, however, it was observed that this relationship was stronger in female SES $\left(r^{2}=\right.$ $0.53)$ and male ST students $\left(r^{2}=0.29\right)$ than male SES students $\left(r^{2}=0.12\right)$. Furthermore, the relationship for female ST students was weak and non-significant $\left(r^{2}=0.08 ; p=0.57\right)$.

For $L 5(T)$ and $L 6(T)$, the overall cohort's relationship was $r^{2}=0.25$, which again was relatively consistent across gender and programme groups $\left(r^{2}=0.25-0.32\right)$. All subgroup relationships were also significant but differed in strength, with female SES students demonstrating a stronger relationship $\left(r^{2}=0.52\right)$ than male SES students $\left(r^{2}=0.21\right)$.

The overall cohort's relationship between $L 4(T)$ and L6(T) was identical to the L5(T) to L6(T) relationship $\left(r^{2}=0.25\right)$. Similarly, no significant discrepancies were observed between gender or programme groups $\left(r^{2}=0.22-0.30\right)$. In the subgroups, male ST students demonstrated the 
strongest relationship $\left(r^{2}=0.46\right)$, followed by female SES $\left(r^{2}=0.34\right)$, female ST $\left(r^{2}=0.22\right)$ and male SES students $\left(r^{2}=0.21\right)$.

\section{Discussion}

The aim of this study was to explore the relationships between research methods assessments and modules across Levels 4-6 of Sport and Exercise Science (SES) and Sports Therapy (ST) degrees at one UK-based HEI. The main findings demonstrated that, overall, females performed better on research methods modules than males, and achieved significantly higher marks in the statistics-based assessment. Comparisons between programmes showed that SES students performed significantly better than ST students across all Level 6 marks. The Level 5 statistics assessment was the most poorly correlated mark with the Level 6 dissertation and was non-significantly correlated in two of the four subgroups, whilst the Level 5 proposal assessment explained the most variance in the dissertation mark.

\section{Gender Differences}

Overall, females' performed $1.6 \%$ better than males, a statistic comparable to the $2 \%$ average gender difference previously reported for undergraduate degree programmes (Sander \& Sanders, 2007). There was also a greater range of marks within the male cohort (52.3) than females (46.7) supporting that males attain more firsts and thirds than females (McNabb et al., 2002). However, within mathematics-science degrees there are mixed views as to who is more successful. Though it has previously been suggested that females perform worse in maths-science subjects (McNabb et al., 2002), the present results support the opposite with females in fact out-performing men in statistics modules (Hanna, 2002). In addition, whilst this is proposed to be particularly related to the first year of study (Hanna, 2002), the current findings not only illustrate significant differences between SES males and females at Level 4, but also that females performed $6.7 \%$ better on the statistics module than males at Level 5 . This supports the suggestion from authors such as Spleke (2006) who suggest that both males and females have the ability to develop talent for mathematics and science, due to the fact that mathematical and scientific reasoning skills develop from a set of biologically-based cognitive capabilities. However, it is somewhat in contrast to the large body of research which has been conducted on sterotype threat, particularly related to females and mathematical performance (Spencer et al., 1999). Whilst less research has focused implicitly on how 
sterotyped individuals may overcome this threat, one explanation is that sterotype threat effects (whereby defensive reactions negatively impact on self-integrity) could be reduced or even eradicated completely through focusing on alternative means by which overaching selfesteem needs can be met (i.e. self-affirming) (Steele, 1988; Martens, Johns, Greenberg \& Schimel, 2006). In this way, it can be suggested that the female SES students were somehow able to self-affirm, overcome the stereoypes associated with gender and maths, and outperform their male counterparts.

Interestingly, despite performing better within the current study, females are said to earn more degrees in humanities and life sciences, and are less likely to choose to study maths (Vincent-Lancrin, 2008). On the other hand their male counterparts favour maths and inorganic science degrees, and have been shown to excel in mathematical and spatial reasoning abilities (Benbow, Lubinski Shea \& Eftekhari-Sanjani, 2000). On a whole it is reported that women are outnumbered by men at universities (Francis, Robson \& Read 2001), and that men are less likely to drop out (Garner, 2009). In physical science subjects specifically, there are significant differences between male and female cohorts (7.8:1) (Webb et al., 2002), and previous research suggests that females are under-represented in research method teaching roles, perhaps fashioning the existing gender discrimination towards females for research jobs (Clark, 1996). Despite a male to female ratio of 1.6:1 in the current study, the superior performance from the females at Levels 4 and 5 refutes the suggestion that female students underperform in more male-dominated subjects such as the sciences and engineering (McNabb et al., 2002). This is in spite of the notable negative impact that males are suggested to have on their female counterparts within the learning environment (Philips \& Young, 2011). Such diverse views suggest that the explanation for the gender gap in academic performance is particularly complex and involves interactions between many different considerations (McNabb et al., 2002).

In contrast to superior female performance in $\mathrm{L} 4(\mathrm{~T}), \mathrm{L} 5(\mathrm{~T})$ and $\mathrm{L} 5(\mathrm{STATS})$, males demonstrated a significant improvement at Level 6 and averaged 1.8\% higher marks than females. As L6(T) was worth a relatively large proportion of the overall degree, it is likely that males attained a higher average degree classification. The dissertation module had a heavily weighted written element alongside the research project conducted and therefore could explain the reversed 
gender trend at Level 6 as males are suggested to be more likely to adopt a bold writing style which is expected to be rewarded by examiners/markers (Robson \& Read, 2001). This would align with previous research and the proposal that males outperforming females can be explained by writing style effects and the interaction of personality characteristics and assessment styles (Sander \& Sanders, 2007). This ambiguity between assessments and gender does, however indicate that further research is required to better understand the prevalence of the gender gap across programmes, as well as within modules and assessment types, and the potential impact of these differences on graduate outcomes (Farsides \& Woodfield, 2007).

\section{Programme Differences}

Differences in performance between the SES and ST programmes were also apparent. The SES students outperformed ST students across Level 6, achieving significantly higher marks in L6(PRES), L6(DISS) and L6(T). This can be assumed to be derived from the poorer performances from the female ST students. Whilst the two programmes are within the same domain of Sport, the underpinning knowledge and skills, and exit-level outcomes vary. The modules that are taught on the different degree programmes are diverse, not only in their educational topics, but also in their assessment techniques. For example, the majority of the assessments for ST are practical in nature to align with their exit-level outcome of gaining a professional practitioner qualification. One study demonstrated that ST students perceive clinical and fieldwork type assessments more satisfying and motivating, and reported that perceived relevance significantly influences this motivational state (Seale, Chapman \& Davey, 2000). This assessment experience, limited in the examination of written skills and less motivating, could help explain why the ST students performed worse in the dissertation module than SES students.

In contrast to the vocationally-led delivery of the ST programme, modules in SES embed research concepts throughout the three levels of study which could further explain the superior performance of the SES cohort. Evidence has indicated that in order to understand the methodology and processes of research, you need to engage in research activity (Gladys et al., 2012) and students are most likely to benefit from research when they are actively involved in conducting research projects, whether in part or in whole (Healey, 2005). This 
evidence clearly demonstrates the merits of research-based dissertations for HE students. The results of the current study suggest that although both programmes were taught and assessed on research methodologies, specifically at Level 4 and in L5(STATS), this was not sufficient to significantly contribute to success in the purely research-focussed, dissertation project and therefore, despite the plethora of research which advocates the inclusion of a research-based dissertation at undergraduate level, we suggest that a research-based project may not be ideal for such a vocational degree programme as ST.

Another factor shown to be influential to student perceptions and attitudes to research is that of staff expertise, interest and occupations (Lindsay, Breen \& Jenkins, 2002). Positive views from undergraduate students regarding lecturer research activity have been shown to increase with the quality and quantity of the research conducted by the teaching staff, with benefits such as motivation, enthusiasm and recognition of enhanced knowledge (Lindsay, Breen \& Jenkins, 2002). As the SES lecturing staff at the institution were more research active than the ST staff, the SES students may be more motivated to conduct their own research. As motivation and resultant self-efficacy have been evidenced amongst Sports students to be significant predictors of academic performance (Lane, Devonport \& Milton et al., 2003), the influence of the staffing teams may have played a role in the programme differences at Level 6.

\section{Assessment and Level Relationships}

Statistics and Dissertation Assessments

L5(STATS) was the lowest overall predictor of the dissertation mark (17\%) and the lowest overall mark for all students. Furthermore, an absence of a significant relationship was also observed in the male SES and female ST students. Coefficients were seen to be lowest in males (6\%) than females (15\%) which further supports the previous argument of important gender connotations within this context. The SES and ST programmes were similar in their performance and correlations with dissertation marks.

It has been proposed that the problems students experience with statistics may lead to low degree marks and create difficulties with their research projects (Gladys et al., 2012). Whilst the present results do not support this, with the poorest correlation between L5(STATS) and L6(DISS), it begins to question the alignment of the actual content of the statistics assessment 
or teaching practices in relation to the dissertation level outcome. The poor relationship perhaps suggests that the content and context of the topics which relate to this assessment are not sufficient to prepare the students for their final year research project. The overall mean mark for the statistics assessment is also lower than all other Level 5 and 6 marks, indicating that students typically perform worse than usual in this piece of work.

\section{Alignment between Levels}

Whilst it was expected that performance at each level would be positively correlated with the other levels, the overall relationships between Levels 4-6 modules differed across gender, programme and cohort. As an overall cohort, modules at Levels 4-5, 5-6, and 4-6 were all correlated, explaining $17-25 \%$ of variance. Contrastingly, for the female ST subgroup the mark achieved at Level 4 did not have a significant relationship with the Level 5 mark. This suggests that despite the Level 4 module being designed as a precursor to the Level 5 module, a misalignment exists between the research methods modules, and the diversity within the cohorts may have caused the female ST students to be greater affected. This is a potential avenue for future research and one in which is of interest considering Female ST are the lowest achievers of the four cohorts.

The trend in performance across Levels 4-6 also differed between males and females. As previously discussed, females outperformed males at Levels 4 and 5 but males improved at Level 6. Female performance was consistent across the degree, with average marks only varying by $0.7 \%$, whereas males were seen to improve significantly at Level 6 with a range of 4.9\% between levels. Research in HE has demonstrated that year-to-year persistence is commonly higher amongst females, supporting the trends demonstrated within this study (Seidman, 2005). Males are also significantly more likely to have difficulty in finding motivation to study in the first year of their degree (Krause, Hartley, James \& Mclnnis, 2005). Contrastingly, academic success in the first year of study is deemed pivotal to longer term persistence and overall degree classification and graduation rate (Seidman, 2005). The trends in male performance across Levels 4-6 refute this relationship, where they performed poorly at Level 4 but demonstrated a greater augmentation in performance to achieve the highest marks at Level 6. Institutions should therefore assess whether the variation in year-on-year progression between genders is simply a function of different entry-level characteristics 
which render females more likely to succeed, or whether this indicates that the institution itself serves females more effectively than males.

\section{Implications and Future Recommendations}

Until now, little attention has been paid to the objective understanding of the alignment between research methods modules and the important dissertation project. Further work is needed to identify the appropriateness of the learning outcomes of Level 4 and 5 assessments in their alignment with the Level 6 dissertation learning outcomes. Similarly the ability of the assessments in providing students with suitable skill sets and knowledge to produce worthy research projects needs to be evaluated. Attention needs to be paid to the implications of the present study's findings, highlighting differences in research methods performance between genders and programmes, which are important due to the wider impact beyond degree classifications (NcNabb et al., 2002). This level of diversity in gender participation in different degree programmes should be acknowledged across all stages of curriculum design, planning and delivery (Greenbank, 2006; Reay, David \& Ball, 2005).

Consequently, our findings imply that research methods modules and assessments need to recognise the diverse nature of the student cohorts; acknowledging differences in vocational (ST) versus more academic-based programmes (SES), and disparities in learning styles between genders. It is argued that students would react more positively to research if the concepts were presented in an applied or clinical context (Gladys et al., 2012), although contradictory views are that students will still have little interest in research regardless of it context (Sizemore \& Lewandowski, 2011). A possible strategy to overcome these issues is for academics to gain understanding of student's perceptions of learning, skill transfer and appropriateness of research within their occupational skills and then use this knowledge to enhance teaching and learning (Burke Jones \& Doherty, 2005). For example, if students value the gaining of practical and laboratory experience, attempts could be made to allow students to collect their own data which could then be analysed as part of a research methods based assignment. However as noted by Lane and Whyte (2006), providing students with real laboratory experience often presents a challenge for lecturers of sports-based courses.

Whilst beyond the scope of the current study, it should be acknowledged that the variability in other modules taught on the two programmes could inarguably have a confounding 
influence on the students' performance on the research methods modules. For example, the limited inclusion of written assessments in ST could have influenced the transfer of knowledge upon their final dissertation assessment. In addition, while the greater number of males compared to females involved in the study is not atypical of many sports-based degree programmes, this can also be considered a limitation of the study.

It is well-documented that there is a stigma around research methods and statistics which could stem from a viewpoint of uninteresting applicability outside of the typical numbers and equations, but also from the associated difficulty (Schutz et al., 1984; Campisi \& Finn, 2011). Students are often reluctant to learn research methods and statistics, with their reluctance manifested in the form of anxiety about mathematics (Williams, 2010). Prior experience of maths however has been suggested to positively influence success and increase student's attitudes towards the subject (Elmore, 1993), with performance on statistics assessments clearly shown to be related to students' attitudes towards statistics (Dempster \& McCorry, 2009). Attitudes have also been found to have a stronger relationship with assessment outcomes than previous experience (Dempster \& McCorry, 2009), therefore interventions should be considered to rectify these negative attitudes.

This study provided a quantitative appraisal of academic performance, adding to the current body of knowledge which has typically adopted qualitative methods of analysis. Future research should consider mixed-methods approaches in the investigation of how well degree programmes prepare students for dissertation projects; triangulating parameters such as academic performance, student satisfaction and motivation, and student characteristics. This approach is recommended for other modules, programmes and institutions to further explore the alignment of assessments across modules and levels of study.

\section{Conclusion}

This study demonstrated that differences exist in research methods performance between males and females, and SES and ST undergraduate degree programmes. Contrary to previous research, females performed better than males in the statistics assessment, and ST students were outperformed by SES students at Level 6 . These findings emphasise that curriculum design in $\mathrm{HE}$ needs to acknowledge diversity between genders, sports programmes and learning styles. 
Relationships between the research methods modules were weaker than anticipated, particularly the statistics assessment and dissertation project. This questions the alignment of the learning approaches and assessment criteria leading up to the Level 6 summative project. The results from the current study support that the statistics module taught on Sports programmes may benefit from a more critical examination of its delivery, assessment and alignment.

\section{Acknowledgements}

We would like to thank Paul Greenbank (Edge Hill University, UK) for feedback on a draft of this article. We would also like to thank staff from the Department of Sport and Physical Activity for their input and support with the obtaining of data and production of the paper.

\section{References}

Ball, C. T., and L. E. Pelco. 2006. Teaching Research Methods to Undergraduate Psychology Students Using an Active Cooperative Learning Approach. International Journal of Teaching and Learning in Higher Education 17: 147-154

Benbow, C. P., Lubinski, D., Shea, D. L., \& Eftekhari-Sanjani, H. 2000. Sex differences in mathematical reasoning ability: Their status 20 years later. Psychological Science 11 (6): 474480.

Benson, A., \& Blackman, D. 2003. Can research methods ever be interesting? Active Learning in Higher Education 4 (1): 39-55

Bostock, J. \& Wood, J. 2012. Teaching 14-19: A Handbook: A Handbook. New York: McGrawHill International.

Braguglia, K. H., \& Jackson, K. A. 2012. Teaching Research Methodology Using a Projectbased Three Programme Sequence: Critical Reflections on Practice. American Journal of Business Education 5: 347-352

Brennan, J., Durazzi, N., \& Sene, T. 2013. Things we know and don't know about the Wider Benefits of Higher Education: A review of the recent literature. London, UK: London School of Economics and Political Science 
Burke, V., Jones, I., \& Doherty, M. 2005. Analysing student perceptions of transferable skills via undergraduate degree programmes. Active Learning in Higher Education 6(2): 132-144.

Clark, M. 1996. Mathematics, women and education in New Zealand. Towards Gender Equity in Mathematics Education, pp 257-270, In Hanna, G. 2002. Towards gender equity in mathematics education. An ICMI study. Available at: http://www.springer.com/gb/book/9780792339212

Dempster, M., \& McCorry, N. K. 2009. The role of previous experience and attitudes toward statistics in statistics assessment outcomes among undergraduate psychology students. Journal of Statistics Education 17(2), 1-7.

Edwards, D. F. \& Thatcher, J. 2004. A student-centred tutor-led approach to teaching research methods. Journal of Further \& Higher Education 28 (2): 195-206.

Elmore, P. B. 1993. Statistics Achievement: A Function of Attitudes and Related Experiences.

Farsides, T., \& Woodfield, R. 2007. Individual and gender differences in 'good' and 'first-class' undergraduate degree performance. British Journal of Psychology 98: 467-483.

Francis, B., Robson, J., \& Read, B. 2001. An analysis of undergraduate writing styles in the context of gender and achievement. Studies in Higher Education 26: 313-326

Garner, R. 2009. It's academic: university women are beating men at almost everything. Independent online. Available at:

http://www.independent.co.uk/news/education/education-news/its-academic-universitywomen-are-beating-men-at-almost-everything-1693493.html. [Accessed on: 16/06/2015].

Gladys, S., Nicholas, Z., \& Crispen, B. 2012. Undergraduate Students' Views on Their Learning of Research Methods and Statistics (RMS) Programme: Challenges and Alternative Strategies. International Journal of Social Science Tomorrow 1 (3): 1-9

Greenbank, P. 2006. The evolution of government policy on widening participation. Higher Education Quarterly 60 (2): 141-166.

Haigh, M., \& Clifford, V. A. (2011). Integral vision: A multi-perspective approach to the recognition of graduate attributes. Higher Education Research and Development 30 (5): 573584. 
Hanna, G 2002. Towards gender equity in mathematics education. An ICMI study. Available at: http://www.springer.com/gb/book/9780792339212

Healey, M., 2005. Linking Research and Teaching to Benefit Student Learning. Journal of Geography in Higher Education, 29 (2): 183-201

Krause, KL, Hartley, R., James, R., \& Mclnnis, C. 2005. The first year experience in Australian universities: Findings from a decade of national studies (p. 4). Melbourne: Centre for the Study of Higher Education, University of Melbourne. Available at: http://www.griffith.edu.au/_data/assets/pdf_file/0006/37491/FYEReport05.pdf

Lane, A. M., Devonport, T. J., Milton, K. E., \& Williams, L. C. 2003. Self-efficacy and dissertation performance among sport students. Journal of Hospitality, Leisure, Sport and Tourism Education 2 (2): 59-66

Lane, A. M., \& Whyte, G. P. 2006. From Education to Application: Sport and Exercise Sciences Courses in the Preparation of Applied Sport Scientists. Journal of Hospitality, Leisure, Sport and Tourism Education 5 (2): 89-93

Leathwood, C., \& O'Connell, P. 2003. It's a struggle: the construction of the new student in higher education. Journal of Education Policy 18 (6): 597-615

Lehti, S., \& Lehtinen. E. 2005. Computer-supported Problem-based Learning in the Research Methodology Domain. Scandinavian Journal of Educational Research 49 (3): 297-324

Lindsay, R., Breen, R., \& Jenkins, A. 2002. Academic research and teaching quality: the views of undergraduate and postgraduate students. Studies in Higher Education 27 (3): 309-327

Marginson, S., 2016. The worldwide trend to high participation higher education: dynamics of social stratification in inclusive systems. Studies in Higher Education: 1-22. DOI: 10.1007/s10734-016-0016-x

Martens, A., Johns, M., Greenberg, J., Schimel, J., 2006. Combating stereotype threat: The effect of self-affirmation on women's intellectual performance. Journal of Experimental Social Psychology 42: 236-243.

McNabb, R., Pal, S., \& Loanes, P. 2002. Gender Differences in Educational Attainment: The Case of University Students in England and Wales. Economica 6(9): 481-503

Phillips, A., \& Young, I. 2011.That's what she said: Women students' experiences of 'lad culture' in higher education. London: NUS 
Reay, D., David, M. E., \& Ball, S. J. 2005. Degrees of choice: Class, race, gender and higher education. Trentham Books. Oxford.

Sander, P., and Sanders. L. 2007. Gender, psychology students and higher education. Psychology Learning \& Teaching 6 (1): 33-36

Seale, J. K., Chapman, J., \& Davey, C. 2000. The influence of assessments on students' motivation to learn in a therapy degree programme. Medical Education 34 (8): 614-621.

Seidman A, 2012. College student retention: Formula for student success. Rowman and Littlefield Publishers. USA

Schutt, R., Blalock, H.M., and Wagenaar, T. C. 1984. Goals and means for research methods programmes. Sociology 11 (3): 235-258

Schutz, P. A., Drogosz, L. M., White, V. E., \& Distefano, C. 1998. Prior knowledge, attitude, and strategy use in an introduction to statistics programme. Learning and Individual Differences 10 (4): 291-308

Sizemore, O. J., \& Lewandowski, G. W. 2011. Lesson learned: Using clinical examples for teaching research methods. Psychology Learning \& Teaching 10 (1): 25-31

Spencer, S. J., Steele, C. M., \& Quinn, D. M. 1999. Stereotype threat and women's math performance. Journal of Experimental Social Psychology. 35: 4-28

Steele, C. M, 1988. The psychology of self-affirmation: Sustaining the integrity of the self. In L. Berkowitz (Ed.). Advances in experimental social psychology (Vol. 21, pp. 261-302). New York: Academic Press.

Vincent-Lancrin, S. 2008. The Reversal of Gender Inequalities in Higher Education: An Ongoing Trend. Higher Education to 2030. Volume 1: Demography. New York: OECD: 265-298

UCAS. 2013. Application Cycle: End of Cycle Report UCAS Analysis and Research. December 2013. http://www.ucas.com/sites/default/files/ucas-2013-end-of-cycle-report.pdf

Wagner, C., M. Garner, and B. Kawulich. 2011. The State of the Art of Teaching Research Methods in the Social Sciences: Towards a Pedagogical Culture. Studies in Higher Education 36 (1): 75-88 
Webb, R. M., Lubinski, D., and Pearson Benbow, C. 2002. Mathematically Facile Adolescents with Math-Science Aspirations: New Perspectives on Their Educational and Vocational Development. Journal of Educational Psychology 94 (4): 785-794

Williams, A. S. 2010. Statistics Anxiety and Instructor Immediacy. Journal of Statistics Education 18 (2): 1-18 